\title{
Correlation Between Parathyroid Hormone Levels with Urinary Magnesium Excretion in Patients with Non-Dialysis Dependent Chronic Kidney Disease
}

This article was published in the following Dove Press journal:

International Journal of Nephrology and Renovascular Disease

Raimunda Sheyla Carneiro Dias, (ID Dyego José de Araújo Brito,' Elisângela Milhomem dos Santos, (iD) ${ }^{2}$ Rayanna Cadilhe de Oliveira Costa, (D) Andrea Martins Melo Fontenele, (ID) Elane Viana Hortegal Furtado,' Joyce Santos Lages,

Alcione Miranda dos Santos, iD $^{3}$ Elton Jonh Freitas Santos, (ID) Érika Cristina Ribeiro de Lima Carneiro,' Maria Célia Cruz Diniz, (D) Carla Déa Trindade Barbosa, (ID Alessandra Costa de Sales Muniz, (ID) Ana Karina Teixeira da Cunha França, (iD $)^{3}$ Natalino Salgado Filho, (iD) ${ }^{4}$ Denizar Vianna Araújo, (iD) Mário Bernardo-Filho (iD)

'Center for Prevention of Kidney Diseases, University Hospital of the Federal University of Maranhão, São Luís, MA, Brazil; ${ }^{2}$ Nursing Department, Federal University of Maranhão, São Luís, MA, Brazil; ${ }^{3}$ Public Health Department, Federal University of Maranhão, São Luís, MA Brazil; ${ }^{4}$ Department of Medicine I, Federal University of Maranhão, São Luís, MA, Brazil; ${ }^{5}$ Department of Internal Medicine, University of the State of Rio de Janeiro, Rio de Janeiro, RJ, Brazil; ' ${ }^{6}$ aboratory of Mechanical Vibrations and Integrative Practices, Department of Biophysics and Biometrics, Institute of Biology Roberto Alcântara Gomes and Polyclinic Américo Piquet Carneiro, University of the State of Rio de Janeiro, Rio de Janeiro, RJ, Brazil
Correspondence: Raimunda Sheyla

Carneiro Dias

Tel +5598981545296

Emailsheylak75@yahoo.com.br
Background: Disorders of mineral metabolism occur in most patients with chronic kidney disease (CKD). The aim of this work was to correlate parathyroid hormone (PTH) levels with urinary magnesium excretion in patients with non-dialysis dependent CKD.

Methods: Cross-sectional study. Concentrations of creatinine, magnesium, calcium, phosphate, parathyroid hormone $(\mathrm{PTH}), 25$-hydroxyvitamin $\mathrm{D}[25(\mathrm{OH}) \mathrm{D}]$ and alkaline phosphatase (ALP) were determined in blood samples. The assessment of urinary magnesium levels was performed by means of total daily excretion and by the excretion fraction (FEMg).

Results: The study evaluated 163 patients with a mean age of $60.7 \pm 11.7$ years and $51.0 \%$ were male. In the highest quartile of PTH $(>89.5 \mathrm{pg} / \mathrm{mL})$, the mean levels of FEMg and ALP were higher $(\mathrm{p}<0.05)$. In the unadjusted regression analysis, the following variables were related to serum PTH levels: FEMg (odds ratio $(\mathrm{OR})=1.12 ; 95 \%$ confidence intervals $(\mathrm{CI})$ : $1.02-1.23)$, calcium $(\mathrm{OR}=0.45 ; 95 \%$ CI: $0.22-0.90)$, ALP $(\mathrm{OR}=1.02 ; 95 \%$ CI: $1.00-1.03)$ and eGFR (OR $=0.92 ; 95 \%$ CI: $1.00-1.03)$. After an adjusted analysis, only one FEMg and ALP will remain correlated with PTH.

Conclusion: In patients with non-dialysis dependent CKD, FEMg and ALP were some variables that remained associated with PTH.

Keywords: magnesium, parathyroid hormone, kidney diseases

\section{Background}

Chronic kidney disease (CKD) is a major public health problem and is characterized by a slow progressive and irreversible loss of kidney function. ${ }^{1}$ With the progression of kidney disease, changes in mineral metabolism are observed, such as hypocalcaemia, hyperphosphatemia, decreased levels of 1.25-dihydroxyvitamin D and elevated parathyroid hormone (PTH), constituting secondary hyperparathyroidism. ${ }^{2,3}$

Disorders of mineral metabolism that occur in almost all patients with CKD in the most advanced stages of the disease are associated with bone loss and fractures, cardiovascular disease, inflammation and increased mortality. Although calcium and vitamin $\mathrm{D}$ have been the focus of bone health, other vitamins and minerals have been investigated. ${ }^{4}$ Magnesium $(\mathrm{Mg})$ has attracted the interest of researchers, as a significant association has been identified between bone mineral density and levels of $\mathrm{Mg}$, an essential micronutrient with a wide range of metabolic, structural and regulatory functions. ${ }^{5-7}$ 
The kidneys are the main organs involved in magnesium homeostasis, since they control its serum concentration mainly by modulating excretion in the urine. ${ }^{7,8}$ Studies have shown that the magnesium excretion fraction (FEMg) is a sensitive and useful marker for detecting early abnormalities in the kidney's tubulointerstitial structure, like tubular lesion marker even in individuals without chronic kidney disease. ${ }^{9,10}$

The importance of $\mathrm{Mg}$ is well known, although it has not yet received the necessary attention in clinical practice. As CKD progresses, the levels of PTH increase, which acts as a uremic toxin and can contribute to disorders in the metabolism of minerals. ${ }^{2}$ Although the literature has shown an association between the levels of PTH and serum $\mathrm{Mg}$, the urinary excretion of $\mathrm{Mg}$ is not routinely evaluated, and most studies are performed with patients on dialysis. The hypothesis of this investigation is that the increase in serum levels of PTH is correlated with urinary excretion of $\mathrm{Mg}$ in patients with non-dialysis CKD.

\section{Methods}

\section{Study Design and Participants}

Cross-sectional study developed with non-dialysis CKD patients under treatment followed up at the Center for Prevention of Kidney Diseases (CPDR) of the Federal University of Maranhão (HUUFMA). The protocol, consent form, and study documents were approved by the HUUFMA ethics review board (2.727.940). Trial was conducted in accordance with the Declaration of Helsinki.

The study included patients with chronic kidney disease undergoing non-dialysis treatment in stages $3 \mathrm{~A}, 3 \mathrm{~B}$ and 4 , of both genders aged 20 years or older and who were under follow-up at CPDR-HUUFMA. Pregnant women, carriers of autoimmune, infectious diseases, cancer, acquired immunodeficiency syndrome, thyroid disorders and urinary tract infection, who had hypomagnesaemia in need for replacement, and those with excessive alcohol consumption and using medications such as loop diuretics, proton pomp inhibitors, aminoglycosides, adrenergic beta-agonists, cisplatin, cyclosporine, active vitamin D and theophylline were not included in the study.

Informed consent for participating in the work was obtained from all the examinees prior to their inclusion. Patients answered a standardized questionnaire containing questions related to demographic, socioeconomic characteristics, lifestyle and history of past and current diseases, in addition to the drug therapy in use. To characterize alcohol consumption, the AUDIT (Alcohol-use disorders identification test) was used. ${ }^{11}$

Blood pressure was measured using the oscillometric method (Omron ${ }^{\circledR} 705$-IT device, Japan) and in accordance with the guidelines of the European Hypertension Society, $2018 .{ }^{12}$ Blood samples were collected after a 12 -hr overnight fast and included creatinine (Jaffé reaction colorimetric method), magnesium (colorimetric method with chlorophosphan III), calcium (colorimetric method), phosphate (UV-automated molybdate method), parathyroid hormone (electrochemiluminescence method), 25(OH)D (chemiluminescence method), albumin (Jaffé reaction colorimetric method) and alkaline phosphatase (colorimetric method). When data were expressed in alternative units by external laboratories, the following conversion factors were used: $25-(\mathrm{OH}) \mathrm{D}, \mathrm{ng} / \mathrm{mL}$ to $\mathrm{nmol} / \mathrm{L}: \times 2.496$; $\mathrm{PTH}$, $\mathrm{pg} / \mathrm{mL}$ to $\mathrm{pmol} / \mathrm{L}: \times 0.1064$; Calcium, $\mathrm{mg} / \mathrm{dL}$ to $\mathrm{mmol} / \mathrm{L}: \times$ 0.2495; Phosphate, $\mathrm{mg} / \mathrm{dL}$ to $\mathrm{mmol} / \mathrm{L}: \times 0.3229$; Magnesium, $\mathrm{mg} / \mathrm{dL}$ to $\mathrm{mmol} / \mathrm{L}: \times 0.4105$.

Twenty-four-hour urine was used to measure urinary magnesium and creatinine excretion. The assessment of urinary magnesium levels was performed by means of total daily excretion and the fraction of excretion. The calculation of the urinary magnesium excretion fraction was performed using the following formula: [MgU x CrS $] /[(0.7 \mathrm{xMgS}) \times \mathrm{CrU}]$ x $100,{ }^{13}$ where $\mathrm{MgU}=$ urinary magnesium; $\mathrm{CrS}=$ serum creatinine; $\mathrm{MgS}=$ serum magnesium; $\mathrm{CrU}=$ urinary creatinine. Values above $6.1 \%$ were considered altered. ${ }^{9}$ The samples of 24-hr urine with a volume below $400 \mathrm{~mL}$ or with urinary creatinine $<15 \mathrm{~mL} / \mathrm{Kg} / 24 \mathrm{~h}$ (men) and $<10 \mathrm{~mL} / \mathrm{Kg} /$ $24 \mathrm{~h}$ (women) were considered due to the possibility of error in the collection.

For the definition of CKD, two previous assessments of renal function were considered with a minimum interval of 3 months, as instructed by KDIGO. ${ }^{14}$ Glomerular filtration rate (GFR) was estimated using the formula derived from the CKD-EPI study, ${ }^{15}$ using creatinine as a reference for the calculation. From the results found, it was possible to obtain CKD staging.

The assessment of nutritional status was performed by means of the body mass index (BMI), obtained by the ratio between body mass and height square, and the classification proposed by the World Health Organization ${ }^{16}$ for adults and that of LIPSCHITZ ${ }^{17}$ for the elderly.

\section{Statistical Analysis}

In the statistical analysis of the data, a descriptive analysis was performed to characterize the patients. Categorical 
variables were presented using frequencies and percentages and quantitative variables using means and standard deviations (mean $\pm \mathrm{SD}$ ). The normality of the variables was tested by the Shapiro-Wilk test. To assess the variables studied among the PTH quartile analysis of variance (ANOVA) or Kruskal-Wallis was performed. Pearson or Spearman linear correlation coefficient analysis was used to assess the degree of relationship between two quantitative variables (Figure 1). Logistic regression models were constructed for the PTH response variable (<quartile 4 ; $\geq$ quartile 4). All variables studied were considered in the univariate model, and the final model was adjusted for the variables clinically related to PTH $(25(\mathrm{OH}) \mathrm{D}$ and phosphate) and the variables that presented $p<0.10$ in the univariate analysis. Odds ratio (OR) and its confidence intervals were obtained $(95 \% \mathrm{CI})$. Statistical significance was set at a p-value $<0.05$, and all analyses were performed using SPSS statistical software (Version 21; IBM Corporation, Chicago, IL).

\section{Results}

The present study evaluated 163 patients with a mean age of $60.7 \pm 11.7$ years and male individuals prevailed (51.0\%). Among those evaluated, $15.3 \%$ consumed alcoholic beverages, $6.7 \%$ smokers, $50.3 \%$ practiced physical activity and $57.1 \%$ were overweight according to the BMI. Arterial hypertension was present in $89.0 \%$ of patients, $45.4 \%$ were diabetic and $68.7 \%$ were in stage 3 (3A and $3 \mathrm{~B}$ ) of CKD (Table 1).

Most patients $(68.7 \%)$ were in stage $3 \mathrm{~A}$ and 3B (eGFR 59-30 $\mathrm{mL} / \mathrm{min} / 1.73 \mathrm{~m}^{2}$ ) with an average eGFR of $37.6 \mathrm{~mL} / \mathrm{min} / 1.73 \mathrm{~m}^{2}$. The serum levels of magnesium, calcium, phosphate and vitamin D were within normal parameters. On the other hand, FEMg and serum levels of alkaline phosphatase and PTH were increased (Table 1).

Table 2 shows the biochemical indicators according to PTH quartiles. In the highest quartile of PTH $(>89.5 \mathrm{pg} / \mathrm{mL})$, the mean levels of FEMg and alkaline phosphatase were higher $(\mathrm{p}<0.05)$, as well as the levels of serum calcium and eGFR were lower $(\mathrm{p}<0.05)$.
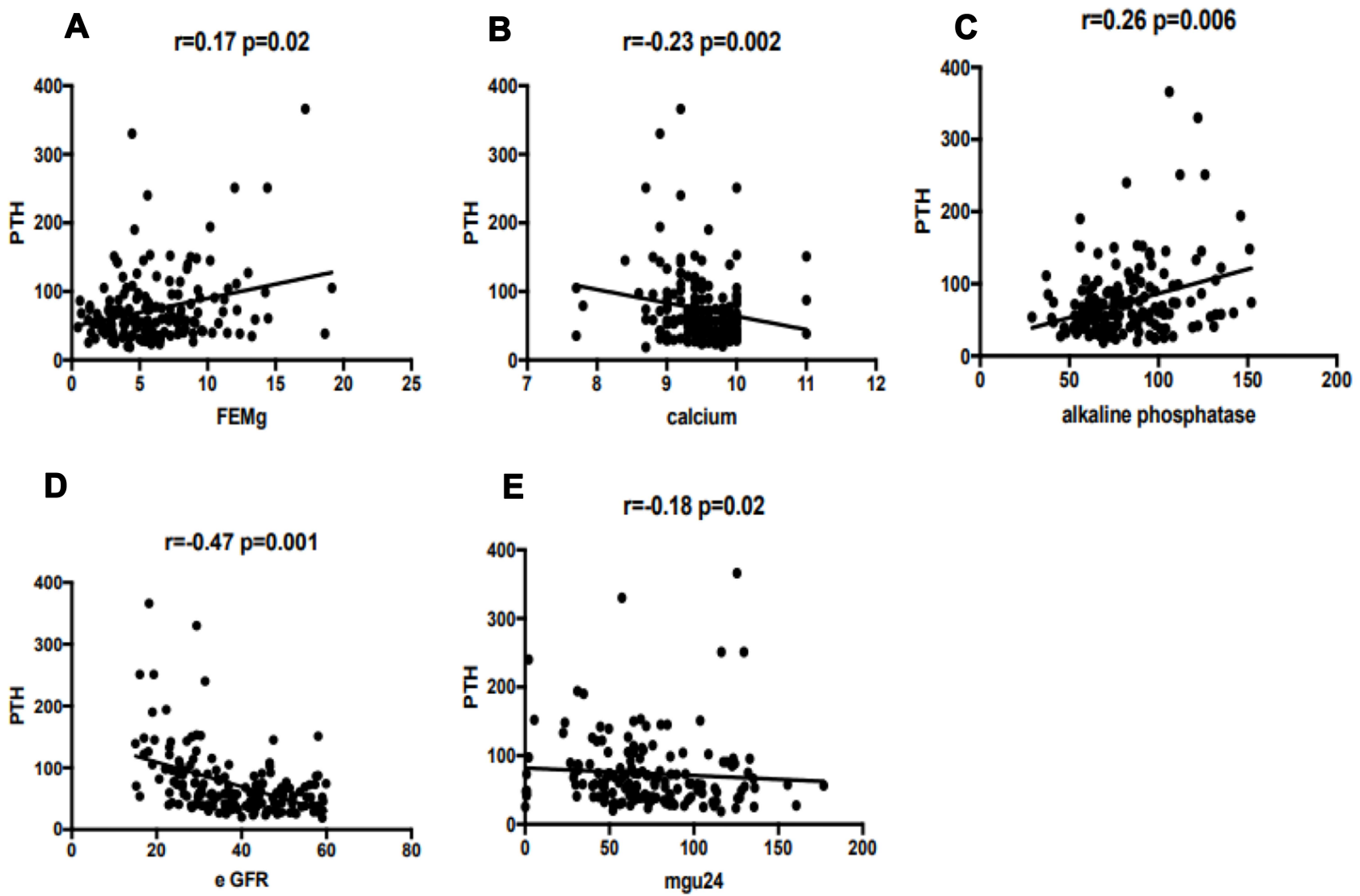

Figure I Linear correlation between PTH with FEMg (A), total calcium (B), alkaline phosphatase (C) estimated Glomerular Filtration Rate (D) and urinary magnesium 24hs (E) in non-dialysis CKD patients.

Notes: Figure I demonstrates the correlations between laboratory variables and serum PTH levels. There was a positive correlation between PTH and alkaline phosphatase $(r=0.26 ; p=0.006)$ and FEMg $(r=0.17 ; p=0.020)$. Calcium $(r=-0.23 ; p=0.002), 24-h r$ urinary magnesium $(r=-0.18 ; p=0.020)$ and eGFR $(r=-0.47 ; p=0.001)$ showed a negative correlation with parathyroid hormone.

Abbreviations: FEMg, magnesium excretion fraction; eGFR, estimated glomerular filtration rate; Mgu24, urinary magnesium 24hs. 
Table I Sociodemographic, Lifestyle and Clinical Characteristics of the Study Population

\begin{tabular}{|c|c|c|c|}
\hline Variables & $\mathbf{n}$ & $\%$ & Mean \pm SD \\
\hline Age (years) & & & $60.7 \pm 11.7$ \\
\hline $20-44$ & 16 & 9.8 & \\
\hline $45-59$ & 45 & 27.6 & \\
\hline$>60$ & 102 & 62.6 & \\
\hline \multicolumn{4}{|l|}{ Gender } \\
\hline Male & 85 & 51.0 & \\
\hline Alcohol consumption & 25 & 15.3 & \\
\hline Smoking & II & 6.7 & \\
\hline Physical activity & 82 & 50.3 & \\
\hline Body mass index & & & $27.7 \pm 4.60$ \\
\hline Overweight & 93 & 57.1 & \\
\hline Hypertension & 145 & 89.0 & \\
\hline Diabetes & 74 & 45.4 & \\
\hline eGFR $\left(\mathrm{mL} / \mathrm{min} / 1.73 \mathrm{~m}^{2}\right)$ & & & $37.6 \pm 11.90$ \\
\hline $45-59$ & 49 & 30.0 & \\
\hline $30-44$ & 63 & 38.7 & \\
\hline $15-29$ & 51 & 31.3 & \\
\hline Parathyroid hormone (pg/mL) & & & $74.2 \pm 52.60$ \\
\hline Quartile I (< 39.9) & 41 & 25.15 & \\
\hline Quartile $2(40.0-58.5)$ & $4 I$ & 25.15 & \\
\hline Quartile 3 (58.6-89.5) & 41 & 25.15 & \\
\hline Quartile 4 (> 89.5) & 40 & 24.55 & \\
\hline Magnesium (mg/dL) & & & $2.0 \pm 0.25$ \\
\hline Urinary magnesium (mg/24hs) & & & $71.7 \pm 35.24$ \\
\hline FEMg (\%) & & & $6.2 \pm 3.56$ \\
\hline Alkaline phosphatase (U/L) & & & $81.5 \pm 24.60$ \\
\hline Phosphate (mg/dL) & & & $3.5 \pm 0.60$ \\
\hline Calcium (mg/dL) & & & $9.5 \pm 0.48$ \\
\hline 25-hydroxyvitamin D (ng/dL) & & & $37.7 \pm 12.82$ \\
\hline
\end{tabular}

Notes: Conversion factors: 25 -hydroxyvitamin D, $\mathrm{ng} / \mathrm{mL}$ to $\mathrm{nmol} / \mathrm{L}: \times 2.496$; parathyroid hormone, $\mathrm{pg} / \mathrm{mL}$ to $\mathrm{pmol} / \mathrm{L}: \times 0.1064$; calcium, $\mathrm{mg} / \mathrm{dL}$ to $\mathrm{mmol} / \mathrm{L}: \times 0.2495$; phosphate, $\mathrm{mg} / \mathrm{dL}$ to $\mathrm{mmol} / \mathrm{L}: \times 0.3229$; magnesium, $\mathrm{mg} / \mathrm{dL}$ to $\mathrm{mmol} / \mathrm{L}: \times 0.4105$.

Abbreviations: FEMg, magnesium excretion fraction; eGFR, estimated glomerular filtration rate; PTH, parathyroid hormone.

In the unadjusted regression analysis, the following variables were related to serum PTH levels: FEMg (OR 1.12; 95\% CI: 1.02-1.23), Calcium (OR $=0.45 ; 95 \%$ CI: $0.22-0.90)$, Alkaline phosphatase $(\mathrm{OR}=1.02 ; 95 \% \mathrm{CI}: 1.00-1.03)$ and eGFR (OR $=0.92 ; 95 \%$ CI: 1.00-1.03) (Table 3). After the adjusted analysis, PTH was independently correlated with FEMg $(\mathrm{OR}=1.10 ; 95 \% \mathrm{CI}: 1.01-1.22)$ and alkaline phosphatase $(\mathrm{OR}=1.01 ; 95 \% \mathrm{CI}: 1.00-1.03)$ (Table 3).

\section{Discussion}

In the present study, FEMg was associated with serum PTH levels in patients with non-dialysis CKD. The highest mean FEMg $(8.0 \pm 4.08 \%)$ was identified in the highest PTH quartile $(>89.5 \mathrm{pg} / \mathrm{mL})$. $\mathrm{Mg}$ is the second most abundant intracellular cation and the fourth most abundant cation in the body. ${ }^{18} \mathrm{Mg}$ is a significant component of the mineral phase of bone, plays a critical role in neuromuscular function and is a cofactor in many enzymatic reactions and biological processes. $\mathrm{Mg}$ reduces $\mathrm{PTH}$ secretion mainly when a moderately low calcium concentration is present; $\mathrm{Mg}$ also modulates parathyroid gland function through the positive regulation of major cell receptors, calcium-sensitive receptor, vitamin D receptor and fibroblast-23 growth factor. ${ }^{19}$ According to Dai et al, ${ }^{20}$ PTH improves the absorption of magnesium in the distal tubule, and the increase of FEMg in patients with CKD works as a compensatory mechanism to maintain serum $\mathrm{Mg}$ levels within the normal range. ${ }^{21}$ The deficiency in the production or performance of PTH causes a decrease in the renal excretion of $\mathrm{Mg}$ because PTH causes changes in membrane potential and cell permeability, in order to increase tubular magnesium resorption. ${ }^{22,23}$

In CKD, studies on the relationship between PTH and serum $\mathrm{Mg}$ were performed preferentially in patients on dialysis and showed an inverse association between these variables, ${ }^{24,25}$ but prospective studies on this effect in nondialysis patients investigating urinary levels of $\mathrm{Mg}$ are scarce. To the best of our knowledge, this is the first study that evaluates the association between FEMg and the serum levels of PTH. With progressive renal dysfunction, PTH levels increase, serum calcium decreases and serum $\mathrm{Mg}$ remains, due to increasing FEMg, this is because patients still preserve tubular function. ${ }^{26}$ In dialysis patients, there is a considerable increase in serum $\mathrm{Mg}$ levels that is associated with hyperparathyroidism, but, in the present study, this association was not verified probably because these patients still preserved tubular function (most patients have eGFR 30-60 $\mathrm{mL} / \mathrm{min} / 1.73 \mathrm{~m}^{2}$ ). A recent study with stage 3 and 4 patients found that the serum $\mathrm{Mg}$ was not related to the different stages of the glomerular filtration rate. ${ }^{27}$

The kidneys play an important role in magnesium homeostasis. Under physiological conditions, $70 \%$ to $80 \%$ of plasma magnesium are filtered from glomeruli, and more than $95 \%$ of this ion is reabsorbed along the tubular system by various coordinated transport processes, leaving only $3 \%-$ $5 \%$ that will be excreted in urine. ${ }^{8}$ Anatomically, the main sites of renal magnesium resorption are the proximal tubule $(10 \%-$ $20 \%$ ), the thick ascending portion of the Henle loop (65\%$70 \%)$ and the distal contorted tubule (10\%). ${ }^{28}$ Tubular damage 
Table 2 Biochemical Indicators According to PTH Quartile in Non-Dialysis CKD Patients

\begin{tabular}{|c|c|c|c|c|c|}
\hline & \multicolumn{4}{|c|}{ PTH (pg/mL) } & \multirow[t]{2}{*}{$p$ value } \\
\hline & $\begin{array}{l}\text { QI } \\
(<39.9)\end{array}$ & $\begin{array}{l}\text { Q2 } \\
(40.0-58.5)\end{array}$ & $\begin{array}{l}\text { Q3 } \\
(58.6-89.5)\end{array}$ & $\begin{array}{l}\text { Q4 } \\
(>89.5)\end{array}$ & \\
\hline FEMg (\%) & $6.0 \pm 3.41$ & $5.1 \pm 2.74$ & $5.7 \pm 3.42$ & $8.0 \pm 4.08$ & 0.007 \\
\hline Urinary magnesium (mg/24hs) & $80.9 \pm 31.80$ & $72.0 \pm 41.40$ & $64.7 \pm 31.10$ & $69.0 \pm 36.10$ & 0.206 \\
\hline Magnesium (mg/dL) & $1.9 \pm 0.22$ & $2.0 \pm 0.31$ & $2.0 \pm 0.22$ & $2.0 \pm 0.23$ & 0.214 \\
\hline Calcium (mg/dL) & $9.6 \pm 0.49$ & $9.5 \pm 0.34$ & $9.4 \pm 0.50$ & $9.3 \pm 0.55$ & $0.014^{\mathrm{a}}$ \\
\hline Phosphate (mg/dL) & $3.5 \pm 0.46$ & $3.5 \pm 0.64$ & $3.5 \pm 0.54$ & $3.6 \pm 0.64$ & 0.627 \\
\hline 25-hydroxyvitamin D (ng/dL) & $39.0 \pm 12.80$ & $38.3 \pm 12.00$ & $36.6 \pm 11.90$ & $36.4 \pm 14.60$ & 0.610 \\
\hline Alkaline phosphatase (U/L) & $73.7 \pm 17.60$ & $78.8 \pm 25.60$ & $81.1 \pm 24.50$ & $92.6 \pm 26.90$ & $0.009^{\mathrm{a}}$ \\
\hline eGFR $\left(\mathrm{mg} / \mathrm{min} / \mathrm{l} .73 \mathrm{~m}^{2}\right)$ & $43.3 \pm 9.76$ & $39.3 \pm 12.00$ & $37.9 \pm 12.50$ & $28.6 \pm 10.10$ & $<0.001$ \\
\hline
\end{tabular}

Notes: ${ }^{a}$ Kruskal-Wallis test. Conversion factors: 25 -hydroxyvitamin $\mathrm{D}, \mathrm{ng} / \mathrm{mL}$ to $\mathrm{nmol} / \mathrm{L}: \times 2.496$; parathyroid hormone, $\mathrm{pg} / \mathrm{mL}$ to $\mathrm{pmol} / \mathrm{L}: \times 0.1064 ;$ calcium, $\mathrm{mg} / \mathrm{dL}$ to $\mathrm{mmol} / \mathrm{L}: \times 0.2495$; phosphate, $\mathrm{mg} / \mathrm{dL}$ to $\mathrm{mmol} / \mathrm{L}: \times 0.3229$; magnesium, $\mathrm{mg} / \mathrm{dL}$ to $\mathrm{mmol} / \mathrm{L}: \times 0.4 \mathrm{l} 05$.

Abbreviations: PTH, parathyroid hormone; FEMg, magnesium excretion fraction; eGFR, estimated glomerular filtration rate; QI, quartile I; Q2, quartile 2, Q3, quartile 3; Q4, quartile 4.

Table 3 Logistic Regression Model of the Variables Associated with PTH Quartile 4 in Non-Dialysis CKD Patients

\begin{tabular}{|c|c|c|c|c|c|c|c|c|}
\hline \multirow{3}{*}{$\begin{array}{l}\text { Variables } \\
\text { FEMg (\%) }\end{array}$} & \multicolumn{4}{|c|}{ Non-Adjusted } & \multicolumn{4}{|c|}{ Adjusted } \\
\hline & \multirow{2}{*}{$\begin{array}{l}\text { OR } \\
1.12\end{array}$} & \multicolumn{2}{|c|}{$\mathrm{Cl}$ [95\%] } & \multirow{2}{*}{$\begin{array}{l}p \text { value } \\
0.018\end{array}$} & \multirow{2}{*}{$\begin{array}{l}\text { OR } \\
1.10\end{array}$} & \multicolumn{2}{|c|}{$\mathrm{Cl}$ [95\%] } & \multirow{2}{*}{$\begin{array}{l}p \text { value } \\
0.040\end{array}$} \\
\hline & & 1.02 & 1.23 & & & 1.01 & 1.22 & \\
\hline Calcium (mg/dL) & 0.45 & 0.22 & 0.90 & 0.024 & 0.61 & 0.24 & 1.51 & 0.287 \\
\hline Phosphate (mg/dL) & 1.28 & 073 & 2.24 & 0.393 & 1.00 & 0.54 & 1.88 & 0.987 \\
\hline 25-hydroxyvitamin D (ng/dL) & 0.98 & 0.96 & 1.00 & 0.212 & 0.99 & 0.96 & 1.02 & 0.604 \\
\hline Alkaline phosphatase (U/L) & 1.02 & 1.00 & 1.03 & 0.011 & 1.01 & 1.00 & 1.03 & 0.044 \\
\hline eGFR $\left(\mathrm{mL} / \mathrm{min} / 1.73 \mathrm{~m}^{2}\right)$ & 0.92 & 0.89 & 0.95 & 0.000 & - & - & - & - \\
\hline Male sex & 0.85 & 0.44 & 1.62 & 0.617 & - & - & - & - \\
\hline Etilism (yes) & 0.62 & 0.22 & 1.73 & 0.361 & - & - & - & - \\
\hline Smoking (yes) & 0.20 & 0.02 & 1.65 & 0.136 & - & - & - & - \\
\hline Physical activity (yes) & 1.59 & 0.82 & 3.07 & 0.167 & - & - & - & - \\
\hline Body mass index $\left(\mathrm{kg} / \mathrm{m}^{2}\right)$ & 0.82 & 0.42 & 1.62 & 0.573 & - & - & - & - \\
\hline Presence of diabetes mellitus & 1.05 & 0.55 & 2.03 & $0.87 I$ & - & - & - & - \\
\hline Presence of hypertension & 0.75 & 0.27 & 2.07 & 0.583 & - & - & - & - \\
\hline
\end{tabular}

Notes: Conversion factors: 25 -hydroxyvitamin D, ng/mL to $\mathrm{nmol} / \mathrm{L}: \times 2.496$; calcium, $\mathrm{mg} / \mathrm{dL}$ to $\mathrm{mmol} / \mathrm{L}: \times 0.2495$; phosphate, $\mathrm{mg} / \mathrm{dL}$ to $\mathrm{mmol} / \mathrm{L}: \times 0.3229$.

Abbreviations: $\mathrm{Cl}$, confidence interval; OR, odds ratio; FEMg, magnesium excretion fraction; CKD, chronic kidney disease; eGFR, estimated glomerular filtration rate; PTH, parathyroid hormone.

leads to the development of a tubular glomeruli and decreases the number of functioning nephrons, with consequent reduction of GFR. Tubular-interstitial damage also reduces blood flow in the corresponding region and induces ischemic lesion of nephrons, with reduced renal plasma flow. ${ }^{29,30}$

In the current study, no correlation was observed between the excretion of Mg in 24-hr urine and PTH. The literature has shown that in advanced CKD there is an increase in PTH levels and a reduction in $\mathrm{Mg}$ urinary excretion. As a compensatory mechanism, the FEMg increases as the CKD progresses, maintaining the serum concentrations of $\mathrm{Mg}$ within normal limits. ${ }^{21,24}$ The FEMg has been reported as one of the most sensitive markers in the identification of early stages of tubulointerstitial lesions. ${ }^{9}$ Evidence of increased FEMg in patients with renal disease derives from clinical and experimental studies that have pointed out the fundamental role of the kidney in the regulation of magnesium excretion. $^{26,31}$ In the study by Chie Noiri et al, ${ }^{21}$ the FEMg showed an inverse correlation with the GFR, suggesting that the FEMg is strongly affected by the decrease in the number of functioning nephrons. Another study performed with 111 adults with CKD in Serbia demonstrated that a FEMg value greater than $6.1 \%$ would provide a more accurate estimate for the reduction of the glomerular filtration rate (GFR) below $60 \mathrm{~mL} / \mathrm{min} / 1.73 \mathrm{~m} 2$ in patients with $\mathrm{CKD}$ and without diabetes. ${ }^{9}$ 
This study also demonstrated an association between PTH and ALP levels. ALP is another biochemical marker of CKD that has traditionally been associated with bone remodeling and cardiovascular risk in uremic patients, also increased as renal function decreases. ${ }^{32}$ The mean values of ALP increased as PTH concentrations increased. The combination of low serum levels of PTH and ALP suggests bone disease with low remodeling, while high levels of both present high sensitivity and specificity for the disease with increased bone remodeling, that is, secondary hyperparathyroidism. ${ }^{33,34}$

The progression of CKD leads to changes in mineral metabolism, such as hypocalcemia, hyperphosphatemia, a decrease in levels of vitamin $\mathrm{D}$ and an increase in $\mathrm{PTH}^{35,36}$ In the present study, it was observed that the GFR decreased with the increase in serum PTH levels. Observational data in patients with CKD associated increased levels of PTH with unfavorable results, such as bone abnormalities, cardiovascular diseases and mortality. ${ }^{37,38}$

Secondary hyperparathyroidism and mineral and bone disorders are characterized by complex, multifaceted and still incomplete physiopathology and may be associated with vascular calcifications and low patient survival. ${ }^{39}$ Low dietary calcium and vitamin D intake, as well as inadequate levels of vitamin $\mathrm{D}$, may contribute to high concentrations of $\mathrm{PTH}^{40}$ This investigation has shown a negative correlation between PTH levels and serum calcium concentrations. In addition, the lowest mean calcium $(9.30 \pm 0.55 \mathrm{mg} / \mathrm{dL})$ was observed in the highest PTH quartile $(>89.5 \mathrm{pg} / \mathrm{mL})$. Considering the decisive role of calcium in stimulating PTH synthesis, one would expect that hypocalcemia would require an increase in serum PTH during the course of CKD. ${ }^{35}$

The prevalence of $25(\mathrm{OH}) \mathrm{D}$ deficiency is common in $\mathrm{CKD}$ and is implicated in the progressive increase in PTH, which is observed with declining renal function and leads to secondary hyperparathyroidism, bone mineral disease and increased cardiovascular risk. ${ }^{41}$ In the study, no correlation between PTH and 25(OH)D was observed. This result is similar to that observed by Cuppari et al, ${ }^{42}$ in a cohort that involved 144 patients with CKD who did not yet receive dialysis (CKD stages 2 to 5), demonstrated that the $25(\mathrm{OH}) \mathrm{D}$ levels were not associated with PTH. A prospective and observational cohort performed with patients with non-dialysis CKD in Australia, the authors demonstrated that the higher mean $25(\mathrm{OH}) \mathrm{D}$ did not cancel the increase in $\mathrm{PTH}^{43}$ On the other hand, in the study by Anderson et al, ${ }^{36}$ which analyzed data from electronic records of 9369 individuals in the United States, PTH was inversely but poorly associated with $25(\mathrm{OH}) \mathrm{D}$ levels $(\mathrm{r}=-0.15)$.

This study presents some limitations. First, there was no monitoring of food consumption of $\mathrm{Mg}$ in the study group and urinary excretion of this mineral is associated with its daily intake. Second, the cross-sectional nature of the study prevents the determination of cause and effect relationships.

\section{Conclusion}

This investigation unveiled that, in individuals with chronic kidney disease on non-dialysis treatment, those with higher levels of PTH had higher averages of ALP and FEMg, and lower levels of serum calcium and eGFR. The FEMg and ALP were the only variables independently associated with PTH.

\section{Abbreviations}

ALP, alkaline phosphatase; CKD, chronic kidney disease; PTH, parathyroid hormone; FEMg, magnesium excretion fraction; $\mathrm{Mg}$, magnesium; $\mathrm{MgU}$, urinary magnesium; $\mathrm{CrS}$, serum creatinine; $\mathrm{MgS}$, serum magnesium; $\mathrm{CrU}$, urinary creatinine; GFR, glomerular filtration rate; eGFR, estimated glomerular filtration rate; CKD-EPI, chronic kidney disease-epidemiologic collaboration equation; BMI, body mass index; 25(OH)D, 25-hydroxyvitamin D.

\section{Data Sharing Statement}

Data not yet completed generated. All data from this study will be available as open access after publication of the articles. Any other information may be requested in writing from the chief investigator.

\section{Ethics Approval and Consent to Participate}

The study was approved by the Research Ethics Committee of the University Hospital of the Federal University of Maranhão (n. 2.727.940). All participants had provided written informed consent prior to participation in any study activities.

\section{Author Contributions}

All authors contributed to data analysis, drafting or revising the article, have agreed on the journal to which the article will be submitted, gave final approval of the version to be published, and agree to be accountable for all aspects of the work. 


\section{Funding}

This study was funded by the Research Support National Council for Scientific and Technological Development (CNPq) and Coordination for the Improvement of Higher Education Personnel (CAPES)- Financing Code 001.

\section{Disclosure}

The authors declare that they have no competing interests.

\section{References}

1. Stevens PE, Levin A. Evaluation and management of chronic kidney disease: synopsis of the kidney disease: improving global outcomes 2012 clinical practice guideline. Ann Intern Med. 2013;158 (11):825-830. doi:10.7326/0003-4819-158-11-201306040-00007

2. Durlacher-Betzer K, Hassan A, Levi R, Axelrod J, Silver J, NavehMany T. Interleukin-6 contributes to the increase in fibroblast growth factor 23 expression in acute and chronic kidney disease. Kidney Int. 2018;94(2):315-325. doi:10.1016/j.kint.2018.02.026

3. Andersson P, Rydberg E, Willenheimer R. Primary hyperparathyroidism and heart disease-a review. Eur Heart J. 2004;25 (20):1776-1787. doi:10.1016/j.ehj.2004.07.010

4. Nieves JW. Skeletal effects of nutrients and nutraceuticals, beyond calcium and vitamin D. Osteoporos Int. 2013;24(3):771-786. doi:10.1007/s00198-012-2214-4

5. Ahmed F, Mohammed A. Magnesium: the forgotten electrolyte a review on hypomagnesemia. Med Sci. 2019;7(4):56. doi:10.3390/ medsci7040056

6. Volpe SL. Magnesium in disease prevention and overall health. $A d v$ Nutr. 2013;4(3):378S-83S. doi:10.3945/an.112.003483

7. Jahnen-Dechent W, Ketteler M. Magnesium basics. Clin Kidney J. 2012;5(Suppl 1):i3-i14. doi:10.1093/ndtplus/sfr163

8. Blaine J, Chonchol M, Levi M. Renal control of calcium, phosphate, and magnesium homeostasis. Clin J Am Soc Nephrol. 2015;10 (7):1257-1272. doi:10.2215/CJN.09750913

9. Žeravica R, Ilinčić B, Čabarkapa V, et al. Fractional excretion of magnesium and kidney function parameters in nondiabetic chronic kidney disease. Magnes Res. 2018;31(2):49-57. doi:10.1684/mrh.2018.0437

10. Gheissari A, Andalib A, Labibzadeh N, Modarresi M, Azhir A, Merrikhi A. Fractional excretion of magnesium (FEMg), a marker for tubular dysfunction in children with clinically recovered ischemic acute tubular necrosis. Saudi J Kidney Dis Transpl. 2011;22:476.

11. Arnáiz AG, Bautista JAA, Montesdeoca JMS, Morenoy AMSMJ, Martel AC, León PB. Utilidad diagnóstica del cuestionario alcohol use disorders identification test (AUDIT) para detectar el consumo de alcohol de riesgo en atención primaria. Med Clin. 2001;116 (4):121-124. doi:10.1016/S0025-7753(01)71745-9

12. Williams B, Mancia G, Spiering W, et al. ESC/ESH guidelines for the management of arterial hypertension: the task force for the management of arterial hypertension of the European society of cardiology (ESC) and the European society of hypertension (ESH). Eur Heart J. 2018;39:3021-3104.

13. Vendrame S, Scattolini M, Brito VP. Hipomagnesemia. In: Lopes RD, editor. Equilíbrio Ácido-Base e Hidroeletrolítico. São Paulo: Atheneu; 2009:171-178.

14. Levin A, Stevens PE, Bilous RW, et al. Kidney disease: improving global outcomes (KDIGO) CKD work group. KDIGO 2012 clinical practice guideline for the evaluation and management of chronic kidney disease. Kidney Int Suppl. 2013;3:1-150.
15. Levy AR, Perkins RM, Johnston KM, et al. An epidemiologic model to project the impact of changes in glomerular filtration rate on quality of life and survival among persons with chronic kidney disease. Int J Nephrol Renovasc Dis. 2014;7:271. doi:10.2147/ IJNRD.S58074

16. World Health Organization (WHO). Physical Status: The Use and Interpretation of Anthropometry. Report of a WHO Expert Committee. Geneva; 2000.

17. Lipschitz DA. Screening for nutritional status in the elderly. Prim Care. 1994;21:55-67.

18. Glasdam SM, Glasdam S, Peters GH. The importance of magnesium in the human body. Adv Clin Chem. 2016;169-193.

19. Martin KJ, Gonzalez EA, Slatopolsky E. Clinical consequences and management of hypomagnesemia. Clin J Am Soc Nephrol. 2009;20 (11):2291-2295. doi:10.1681/ASN.2007111194

20. Dai LJ, Ritchie G, Kerstan D, Kang HS, Cole DE, Quamme GA. Magnesium transport in the renal distal convoluted tubule. Physiol Rev. 2001;81(1):51-84. doi:10.1152/physrev.2001.81.1.51

21. Noiri C, Shimizu T, Takayanagi K, et al. Clinical significance of fractional magnesium excretion (FEMg) as a predictor of interstitial nephropathy and its correlation with conventional parameters. Clin Exp Nephrol. 2015;19(6):1071-1078. doi:10.1007/s10157-015-1099-x

22. Cole DC, Quamme GA. Inherited disorders of renal magnesium handling. J Am Soc Nephrol. 2000;11:1937-1947.

23. Vormann J. Magnesium: nutrition and metabolism. Mol Aspects Med. 2003;24(1-3):27-37. doi:10.1016/S0098-2997(02)00089-4

24. Felsenfeld AJ, Levine BS, Rodriguez M. Pathophysiology of calcium, phosphate, and magnesium dysregulation in chronic kidney disease. Semin Dial. 2015;28(6):564-577. doi:10.1111/sdi.12411

25. Navarro-Gonzales JF, Mora-Fernandez C, Garcia-Perez J. Clinical implications of disordered magnesium homeostasis in chronic renal failure and dialysis. Semin Dial. 2009;22(1):37-44. doi:10.1111/ j.1525-139X.2008.00530.x

26. Cunningham J, Rodríguez M, Messa P. Magnesium in chronic kidney disease stages 3 and 4 and in dialysis patients. Clin Kidney J. 2012;5 (Suppl 1):i39-i51. doi:10.1093/ndtplus/sfr166

27. Azem R, Daou R, Bassil E, et al. Serum magnesium, mortality and disease progression in chronic kidney disease. BMC Nephrol. 2020;21(1):49. doi:10.1186/s12882-020-1713-3

28. de Baaij JH, Hoenderop JG, Bindels RJ. Magnesium in man: implications for health and disease. Physiological reviews. 2015;95 (1):1-46. doi:10.1152/physrev.00012.2014

29. Deekajorndech T. A biomarker for detecting early tubulointerstitial disease and ischemia in glomerulonephropathy. Renal Failure. 2007;29:1013-1017. doi:10.1080/08860220701643567

30. Futrakul N, Futrakul P. Biomarker for early renal microvascular and diabetic kidney diseases. Renal Failure. 2017;39(1):505-511. doi:10.1080/0886022X.2017.1323647

31. Quamme GA. Laboratory evaluation of magnesium studies: renal function and free intracellular magnesium concentration. Clinics in Laboratory Medicine. 1993;13:209-223. doi:10.1016/S0272-2712 (18)30470-0

32. Taliercio JJ, Schold JD, Simon JF, et al. Prognostic importance of serum alkaline phosphatase in CKD stages 3-4 in a clinical population. American Journal of Kidney Diseases. 2013;62:703-710. doi:10.1053/j.ajkd.2013.04.012

33. Bover J, Ureña P, Aguilar A, et al. Alkaline phosphatases in the complex chronic kidney disease-mineral and bone disorders. Calcified Tissue International. 2018;103:111-124. doi:10.1007/ s00223-018-0399-z

34. Behets J, Spasovski G, Sterling R, et al. Bone histomorphometry before and after long-term treatment with cinacalcet in dialysis patients with secondary hyperparathyroidism. Kidney International. 2015;87:846-848. doi:10.1038/ki.2014.349 
35. Căpuşă C, Chirculescu B, Vladu I, et al. The prevalence of biochemical abnormalities of chronic kidney disease. Mineral and bone disorders in untreated non-dialysis patients-a multicenter study. Acta Endocrinologica. 2016;12:282. doi:10.4183/aeb.2016.282

36. Anderson JL, Vanwoerkom RC, Horne BD, et al. Parathyroid hormone, vitamin $\mathrm{D}$, renal dysfunction, and cardiovascular disease: dependent or independent risk factors? American Heart Journal. 2011;162:331-339. doi:10.1016/j.ahj.2011.05.005

37. Koc H, Hoser H, Akdag Y, Kendir C, Ersoy FF. Treatment of secondary hyperparathyroidism with paricalcitol in patients with end-stage renal disease undergoing hemodialysis in Turkey: an observational study. International Urology and Nephrology. 2019;51:1261-1270. doi:10.1007/s11255-019-02175-5

38. Tentori F, Wang M, Bieber BA, et al. Recent changes in therapeutic approaches and association with outcomes among patients with secondary hyperparathyroidism on chronic hemodialysis: the DOPPS study. Clinical Journal of the American Society of Nephrology. 2015;10:98-109. doi:10.2215/CJN.12941213

39. Chandran M, Wong J. Secondary and tertiary hyperparathyroidism in chronic kidney disease: an endocrine and renal perspective. Indian Journal of Endocrinology and Metabolism. 2019;23:391. doi:10.4103/ ijem.IJEM_292_19
40. Vieth R, Yasmin L, Paul GW. Age-related changes in the 25-hydroxyvitamin D versus parathyroid hormone relationship suggest a different reason why older adults require more vitamin D. Journal of Clinical Endocrinology and Metabolism. 2003;88:185-191. doi:10.1210/jc.2002-021064

41. Yataru S, Youngberg B, Zdunek S. Vitamin D levels in subjects with or without chronic kidney disease among veterans with diabetes in North East United States. World Journal of Diabetes. 2017;8 (7):346-350. doi:10.4239/wjd.v8.i7.346

42. Cuppari L, Carvalho AB, Draibe SA. Vitamin D status of chronic kidney disease patients living in a sunny country. Journal of Renal Nutrition. 2008;18(5):408-414. doi:10.1053/j.jrn.2008.05.004

43. Petchey WG, Johnson DW, Hawley CM, Isbel NM. Predictors of vitamin $\mathrm{D}$ status in predialysis chronic kidney disease patients: a cross-sectional analysis in a high ultraviolet climate. Journal of Renal Nutrition. 2012;22:400-408. doi:10.1053/j.jrn.2011.08.007
The International Journal of Nephrology and Renovascular Disease is an international, peer-reviewed open-access journal focusing on the pathophysiology of the kidney and vascular supply. Epidemiology, screening, diagnosis, and treatment interventions are covered as well as basic science, biochemical and immunological studies. The manuscript management system is completely online and includes a very quick and fair peer-review system, which is all easy to use. Visit http://www.dovepress.com/testimonials.php to read real quotes from published authors. 